\title{
The scope, funding and publication of musculoskeletal clinical trials performed in Australia
}

Allison M Bourne BSc(Hons), BA, PhD Research Fellow

Samuel L Whittle MB BS(Hons), MClinEpi, FRACP, Senior Consultant Rheumatologist ${ }^{2}$

Bethan L Richards MB BS(Hons), MClinEpi MSportsMed

Rheumatologist, ${ }^{3}$ and Clinical Senior Lecturer

Chris G Maher BAppSc(Phty), PhD Physiotherapist, Director and Professor

Rachelle Buchbinder MB BS(Hons), MSc, PhD Rheumatologist and Director, ${ }^{1}$ and Professor

1 Monash Department of

Clinical Epidemiolog Cabrini Hospital, Melbourne, VIC.

2 The Queen Elizabeth Hospital, Adelaide, SA

3 Institute of

Rheumatology and Orthopaedics, Royal Prince Alfred Hospital, Sydney, NSW.

4 University of Sydney, Sydney, NSW

5 Musculoskeletal Division, George Institute for Global Health, Sydney Medical School, University of Sydney, Sydney, NSW.

6 Department of Epidemiology an Preventive Medicine, School

of Public Health and

Preventive Medicine, Monash University, Melbourne, VIC

rachelle.buchbinder@ monash.edu

doi: 10.5694/mjal3.10907 ccording to the recently published 2010 Global Burden of Disease study, musculoskeletal (MSK) conditions have the fourth greatest impact on the health of the world's population, accounting for $6.8 \%$ of the total disease burden. ${ }^{1}$ In considering disability alone, low back pain has the greatest impact on health, outranking ischaemic heart disease, chronic obstructive pulmonary disease and major depressive illness, with other MSK conditions ranked sixth and osteoarthritis ranked 11th. ${ }^{1}$

In Australia, MSK conditions are the leading contributor to total disability burden $(27.4 \%)$, and are second only to cancer ( $15.3 \%$ versus $16.2 \%)$ when death is also considered. ${ }^{2}$ They are the most common reason for accessing health care services, ${ }^{3}$ and in financial terms, contribute to $7.5 \%$ of total health expenditure (costing around $\$ 4$ billion). ${ }^{4}$ Given their large burden on the Australian population, osteoarthritis, rheumatoid arthritis and osteoporosis were designated National Health Priority Areas (NHPAs) in 2002. ${ }^{5}$ Importantly, the burden from MSK conditions is increasing as the population ages. There is therefore an urgent need to prioritise research on the most effective and affordable strategies to deal with these conditions.

High-quality trials to test these strategies should be informed by factors such as burden of disease, greatest needs of the population, evidence syntheses showing that more research is required, and identification of novel or promising interventions. To facilitate the conduct of large, high-quality Australian MSK clinical trials that address the most pertinent questions with an emphasis on improving the translation of research findings into clinical practice, we have formed the Australian Musculoskeletal Clinical Trials Group (AUSMUSC). To determine the current scope of Australian MSK clinical trials, we identified the MSK trials currently being performed in Australia, including their source of funding and where they are being published.

\section{Current scope of musculoskeletal trials in Australia}

\section{Definition of Australian musculoskeletal trials}

MSK trials were defined as trials in humans which investigate interventions for the treatment or prevention of inflammatory and non-inflammatory arthritis, regional conditions (back, neck, shoulder/arm, elbow/forearm, hip/ thigh, knee/leg, wrist/hand or ankle/foot), gout, osteoporosis or related conditions, autoimmune diseases
- Musculoskeletal conditions are the leading contributors to disability burden globally and account for $27.4 \%$ of total disability burden in Australia. Timely research that addresses important questions relevant to consumers, clinicians and policymakers is critical for reducing the burden associated with these conditions.

- Clinical trials are particularly important for providing information about whether interventions are effective and safe. They are also needed to test strategies for reducing the sizeable delays in translating evidence into practice.

- A review of the current scope of musculoskeletal clinical trials in Australia found that National Health and Medical Research Council funding is disproportionally low compared with the burden of these conditions (averaging 5.8 new trials per year through the project grant scheme over the past 5 years, representing $0.8 \%$ of all project grants and funding, and 5\% of NHMRC clinical trial funding). In the past 2 years, 128 Australian-initiated trials were registered in a trial registry, while about one in 20 randomised trials published in 37 leading general medical and musculoskeletal-specific journals was initiated in Australia. None were implementation trials.

- Relative to the burden of musculoskeletal conditions in Australia, investment in clinical trials is not ideal. While Australian musculoskeletal trialists are productive and internationally competitive, we may not be addressing the most critical issues. There is an urgent need for Australian researchers, clinicians, policymakers and consumers to work collaboratively to prioritise the most important questions, secure appropriate research funding, and undertake well designed trials to ensure we deliver best evidence-informed care and optimal outcomes for people with musculoskeletal conditions.

including systemic lupus erythematosus and scleroderma, and fibromyalgia. We included all trials with an MSK focus (treatment and/or outcome) even if the participants had another primary condition. Pain trials were excluded if the site of pain was not specified and injury trials other than fractures were also excluded. Trials were considered "Australian" if Australian participants were recruited, and "Australian investigator-initiated" if there was an Australian primary contact.

\section{NHMRC funding for musculoskeletal trials over the past 5 years}

We searched the National Health and Medical Research Council (NHMRC) website to identify successful MSK trial grants (including project and program grants) within the 


\begin{tabular}{|c|c|c|c|c|c|}
\hline $\begin{array}{l}\text { Year trial } \\
\text { commenced }\end{array}$ & $\begin{array}{l}\text { NHMRC* project } \\
\text { grants awarded }\end{array}$ & $\begin{array}{l}\text { No. of project grants for MSK } \\
\text { trials (\% of all project grants) }\end{array}$ & $\begin{array}{l}\text { Total NHMRC funding for } \\
\text { project grants }\end{array}$ & $\begin{array}{l}\text { Total NHMRC funding for } \\
\text { clinical trials }\end{array}$ & $\begin{array}{l}\text { NHMRC funding for project grants for } \\
\text { MSK trials ( } \% \text { of all clinical trials) }\end{array}$ \\
\hline 2009 & 688 & $4(0.6 \%)$ & $\$ 357248846$ & $\$ 44705943$ & $\$ 2171800(4.9 \%)$ \\
\hline 2010 & 683 & $6(0.9 \%)$ & $\$ 390715106$ & $\$ 55812016$ & $\$ 4526514(8.1 \%)$ \\
\hline 2011 & 758 & $2(0.3 \%)$ & $\$ 415484352$ & $\$ 64833882$ & $\$ 906723$ (1.4\%) \\
\hline 2012 & 771 & $8(1.0 \%)$ & $\$ 454826481$ & $\$ 83365267$ & $\$ 4140806(5.0 \%)$ \\
\hline 2013 & 731 & $9^{\dagger}(1.2 \%)$ & $\$ 457858034$ & $\$ 105677755$ & $\$ 5866460(5.6 \%)$ \\
\hline Total & 3631 & $29(0.8 \%)$ & $\$ 2076132819$ & $\$ 354394863$ & $\$ 17612303$ (5.0\%) \\
\hline
\end{tabular}

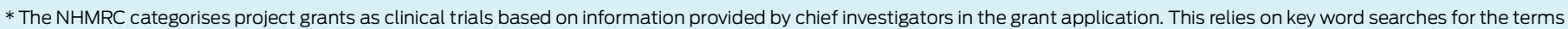

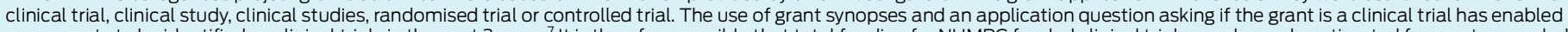

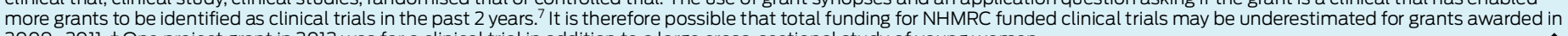
2009-2011. † One project grant in 2013 was for a clinical trial in addition to a large cross-sectional study of young women.

past 5 years (those with funding commencing in 20092013). ${ }^{6}$ The number of successful MSK trial project grants and the amount of funding awarded was compared with the number of grants and amount of funding awarded for all NHMRC-funded clinical trials, and for all NHMRC project grants.

NHMRC project grants have provided funding of more than $\$ 17.6$ million for 29 MSK trials over the past 5 years (range, 2-9 trials per year) (Box). This represents $0.8 \%$ of all project grants funded, $0.8 \%$ of the total funding allocated to project grants ( $\$ 17.6$ million out of $>\$ 2$ billion) and $5.0 \%$ of the total amount of NHMRC funding allocated to clinical trials (\$17.6 million out of \$354 million).

Appendix 1 (online at mja.com.au) summarises details for the 29 MSK trials funded by NHMRC project grants. Over a third (11 trials), were for interventions for osteoarthritis (eight for the knee, two for the hip and one for the big toe). Interventions included drug treatments, physical therapies and exercise, footwear, acupuncture and surgery. There were three trials for low back pain and one trial for sciatica, which investigated treatment with either drugs or psychotherapy; and one trial for neck pain and two for whiplash, which investigated treatment with either exercise or dry needling.

The remaining trials varied widely by condition and intervention.

One program grant for MSK trials has been awarded over the past 5 years. It funded eight trials which investigated interventions related to physiotherapy for regional conditions (Appendix 1).

\section{Australian musculoskeletal trials registered in the past 2 years}

We searched the Australian New Zealand Clinical Trials Registry (ANZCTR) and World Health Organization Clinical Trials Registry Platform to identify all MSK trials (randomised, non-randomised and single-arm), registered within the past 2 years (2011-2012), that are currently recruiting, planning to recruit or had recruited participants in Australia. For the ANZCTR registry we used the advanced search facility and included both randomised and non-randomised allocation to intervention. We searched all trials categorised by the conditions: musculoskeletal, alternative and complementary medicine, anaesthesiology, inflammatory and immune system, inju- ries and accidents, metabolic and endocrine, other, physical medicine and rehabilitation, public health and surgery. We did not limit by sex, age group or recruitment status, and did not exclude healthy volunteers.

For the WHO Clinical Trials Registry, we also conducted an advanced search of both randomised and non-randomised trials, restricting our results to those that listed musculoskeletal, injury, inflammation, endocrine, rehabilitation, surgery, alternative medicine, immune diseases, or public health as the "condition". Since the condition category is not restricted to a set number of conditions as it is in the ANZCTR registry, we performed this search using the key words arthritis, osteoporosis, scleroderma, vasculitis, gout, spondyloarthritis, lupus, back, neck, shoulder, arm, elbow, forearm, wrist, hand, hip, thigh, knee, leg, ankle and foot. Registered trials that listed NHMRC funding were crosschecked with the NHMRC search results.

We identified 191 MSK trials that were recruiting Australian participants registered in the past 2 years (132 registered in the ANZCTR and 59 in the WHO clinical trials registry) (Appendix 2; online at mja.com.au). There were 83 trials (44\%) with industry sponsorship and 63 (33\%) that listed an overseas industry contact person. One hundred and twenty-eight trials (67\%) appeared to be trials initiated within Australia (all but one were registered within the ANZCTR).

The median trial size for Australian investigator-initiated trials was generally smaller than that of all registered trials combined (median, 65 participants; range, 10-1650 participants versus median, 100 participants; range, 10-16300 participants). Of the Australian investigator-initiated trials, two-thirds $(n=86,67.2 \%)$ had a recruitment size of $\leqslant 100$ participants. Over a third $(n=45,35 \%)$ were for osteoarthritis. Two-thirds of these $(n=30)$ related to various aspects of joint replacement or arthroscopy. Another 12 trials $(9 \%)$ were for osteoporosis or related conditions, six trials were for rheumatoid arthritis and one trial was for gout. There were 53 trials $(41 \%)$ for regional conditions, most commonly low back pain $(n=12,9 \%)$, shoulder and arm pain $(n=10,8 \%)$ and neck pain $(n=8,6 \%)$.

Overall, the most common intervention studied was physical therapy and/or exercise $(n=55,43 \%)$, while 33 ( $26 \%)$ were for drug therapies, $23(18 \%)$ were related to surgery, 12 (9\%) investigated a patient education intervention and four trials (3\%) investigated a psychological 
intervention. There were no trials investigating interventions to improve uptake of research findings or guidelines into practice.

\section{Australian musculoskeletal randomised controlled trials published in top international journals in the past 2 years}

We chose journals based on their 2011 impact factor rankings according to Journal Citation Reports (Thomson Reuters) in each of the following subject categories: medicine, general and internal, rheumatology, orthopaedics, rehabilitation and sports sciences. As there was no specific category for osteoporosis we searched the subject category endocrinology and metabolism for journals that include osteoporosis within their scope, and we searched subject category orthopaedics to identify journals that included spine pain within their scope. We included journals where at least one MSK randomised controlled trial (RCT) had been published in 2011 or 2012. Several journals appeared in more than one category and for ease of description we included them in the heading that we thought best described their scope. We limited inclusion to the primary publication of RCTs.

We searched Ovid MEDLINE 2011 and 2012 using the search term "randomised controlled trial" and the journal name. Two authors independently screened the search results and retrieved the full text if necessary. We also searched all issues of journals online and for those with a search facility we searched papers using the term "trial".

We identified 565 published papers reporting the primary results of MSK RCTs in the top 37 (ranked by impact factor) general medical and MSK-specific journals in the past 2 years (Appendix 3; online at mja.com.au). Fiftyseven of these $(10.1 \%)$ included Australian participants (Appendix 4; online at mja.com.au), and 30 (5.3\%) were initiated in Australia. Australian investigator-initiated trials were published across a range of journals, particularly in rheumatology, orthopaedics and rehabilitation.

Almost half (14) were for osteoarthritis and a further 14 were for regional conditions (Appendix 5; online at mja.com.au). Nearly half (14) involved physical therapy interventions, while drug and surgery interventions accounted for 12 . There were no published trials investigating interventions to improve uptake of research findings or guidelines into practice.

\section{Where are the gaps?}

Our data indicate that Australian MSK trialists are productive and internationally competitive. The NHMRC has funded an average of 5.8 new MSK trials per year through the project grant scheme over the past 5 years; 128 Australian-initiated trials were registered in the past 2 years; and about one in 20 MSK RCTs published in leading general medical and MSK-specific journals in the past 2 years was initiated in Australia.

A significant number of Australian-initiated trials were for osteoarthritis. While this is commensurate with its known burden on the population, and its status as an NHPA, there were proportionally fewer trials for osteoporosis and rheumatoid arthritis, both also designated
NHPAs. Despite the ranking of back pain as the leading cause of disability worldwide and in Australia, there were also comparatively fewer trials for back pain, and a paucity of trials for other MSK conditions. Integrating other MSK conditions such as back pain into the NHPA framework could increase their profile and result in more systematic development and implementation of programs aimed at promoting best practice treatment of these conditions. ${ }^{8}$

NHMRC funding for MSK trials was found to be disproportionately low in relation to the size of the burden from MSK conditions in Australia and internationally. A 20002008 review of NHMRC funding found that some of Australia's NHPAs are better funded than others. ${ }^{9}$ The NHMRC has estimated that more than \$216 million has been invested in arthritis and osteoporosis research in the past decade. ${ }^{10}$ While the data may not be directly comparable, as estimated funding is based on identification of chief investigator-provided keywords and titles contained in the NHMRC research database, this appears to be less than the amount invested in other NHPAs such as diabetes (> \$475 million) and cardiovascular disease (\$795 million). In contrast to one NHMRC MSK program grant in the past 5 years, three have been awarded for diabetes and eight for cardiovascular clinical research.

We think it is unlikely that we missed any NHMRCfunded MSK trials, although we have no information about unsuccessful grant applications (as this information is not publicly available). However, it is possible that we underestimated the number of other NHMRC-funded trials, as before 2011 there was no specific category for clinical trials and identification was reliant on a key word and title search of the NHMRC database using the terms clinical trial, clinical study, clinical studies, randomised trial or controlled trial. It is also unlikely that we missed relevant registered Australian MSK trials. While most registered MSK trials are likely to denote themselves as MSK, we also searched other potentially relevant categories. It is also unlikely that we missed relevant Australian MSK trials published in the past 2 years. Two independent reviewers used two different but complementary strategies to identify potentially relevant papers. The scope of trials was also broadly similar across all three components of our scoping project, further supporting the validity of our findings.

There was a wide range of interventions under study, most commonly drug treatments or physical therapies. While the range of current Australian MSK trials likely reflects the interests and expertise of Australian MSK trialists, our review suggests that not all Australian MSK trials reflect priorities based on the greatest burden of disease, the most novel and/or promising interventions and the greatest needs of the population. Many trials may be too small to be of value; many appear to be driven (either directly or indirectly) by commercial imperatives rather than genuine clinical novelty or patient-centred research priorities, and most are unlikely to influence clinical practice. While a significant number included a placebo or usual care comparator, there were no placebocontrolled surgical trials and only one comparing surgery with conservative care. In addition, we identified only one multicentre trial (which involved two states). 


\section{Where to from here?}

Identifying and addressing evidence-practice gaps has been identified as a major NHMRC priority, ${ }^{11}$ yet none of the Australian trials we identified was testing interventions to improve uptake of research findings or guidelines into practice. This is in keeping with a previous study that found scarce high-quality implementation trials addressing nine evidence-practice gaps relating to other conditions, and no indication that this had improved over time. ${ }^{12}$ The NHMRC has now established a Research Translation Faculty to address the challenge of research translation in Australia. ${ }^{13}$ As part of this process, steering groups across major health areas have been tasked with identifying major evidence-practice gaps. While the role of each steering group is to develop a single case for action that the NHMRC could address, this process may also serve to identify priorities for MSK trials based on population needs, to complement and enhance current investigator-initiated trials.

More investment to support the conduct of MSK trials in Australia is needed. This includes infrastructure funding in both the public and private sectors, more support for clinical researcher training and supervision and, importantly, greater buy-in from clinicians and patients. Many studies have identified suboptimal clinician buy-in for clinical research, particularly those directed towards closing evidence-practice gaps. ${ }^{12,14,15}$ The lack of clinician buyin for clinical research directed specifically at improving care suggests the need for a global culture shift towards clinician (and patient) participation in research as a matter of course.

There is also an onus on MSK trialists to ensure that they ask the most important questions. Evidence suggests that this is not consistently the case. ${ }^{16}$ In discussing the mismatch between what clinical researchers do and what patients need in oncology, Liberati has suggested that inclusion of patients and patient advocacy groups, who spend much time in raising awareness and money to support research in the hope of improving care, should be at the centre of redefining the research agenda. ${ }^{17}$ The Arthritis Research UK clinical studies initiative has already taken a strategic approach to prioritising clinical study funding for MSK disorders. ${ }^{18}$ Consultations with consumer representatives and all relevant health care professionals and scientists have led to nationally agreed priorities for MSK clinical trials. It is time to replicate this approach in Australia to ensure that only worthwhile MSK trials are performed and funded.

Acknowledgements: This study was funded by Arthritis and Osteoporosis Victoria. Chris Maher is funded by an Australian Research Council Future Fellowship; Rachelle Buchbinder is partially funded by an Australian NHMRC Practitioner Fellowship.

Competing interests: No relevant disclosures.

Provenance: Not commissioned; externally peer reviewed.

1 Murray CJ, Vos T, Lozano R, et al. Disability-adjusted life years (DALYs) for 291 diseases and injuries in 21 regions, 1990-2010: a systematic analysis for the Global Burden of Disease Study 2010. Lancet 2012; 380: 2197-2223.

2 Vos T, Flaxman AD, Naghavi M, et al. Years lived with disability (YLDs) for 1160 sequelae of 289 diseases and injuries 1990-2010: a systematic analysis for the Global Burden of Disease Study 2010. Lancet 2012; 380: 2163-2196.

3 Australian Institute of Health and Welfare. Arthritis and osteoporosis in Australia 2008. Canberra: AlHW, 2008. (AlHW Cat. No. PHE 106; Arthritis Series No. 8.) http://www.aihw.gov.au/publication-detail/?id=6442468194 (accessed Sep 2013).

4 Australian Institute of Health and Welfare. Health expenditure for arthritis and musculoskeletal conditions, 2004-05. Canberra: AlHW, 2009. (AlHW Cat. No. PHE 115; Arthritis Series No. 10.) http://www.aihw.gov.au/WorkArea/ DownloadAsset.aspx?id=6442459924 (accessed Sep 2013).

5 Australian Institute of Health and Welfare. Arthritis, osteoporosis and other musculoskeletal conditions. http://www.aihw.gov.au/arthritis-andmusculoskeletal-conditions (accessed Sep 2013).

6 National Health and Medical Research Council. Outcomes of funding rounds. http://www.nhmrc.gov.au/grants/outcomes-funding-rounds (accessed Sep 2013)

7 National Health and Medical Research Council. NHMRC funded clinical trials research 2000-2012. http://www.nhmrc.gov.au/grants/research-fundingstatistics-and-data/funding-datasets/clinical-trials (accessed Dec 2013).

8 Briggs AM, Buchbinder R. Back pain: a National Health Priority Area in Australia? Med J Aust 2009; 190: 499-502.

9 Mitchell RJ, McClure RJ, Olivier J, Watson WL. Rational allocation of Australia's research dollars: does the distribution of NHMRC funding by National Health Priority Area reflect actual disease burden? Med J Aust 2009; 191: 648-652.

10 National Health and Medical Research Council. Arthritis and osteoporosis. 2012. http://www.nhmrc.gov.au/node/1493 (accessed Oct 2013).

11 National Health and Medical Research Council. NHMRC Strategic Plan 20132015. Canberra: Commonwealth of Australia, 2012. http://www.nhmrc.gov.au/ files_nhmrc/publications/attachments/nh160_nhmrc_strat_plan_201315.pdf (accessed Oct 2013).

12 Evensen A, Sanson-Fisher R, D'Este C, Fitzgerald M. Trends in publications regarding evidence-practice gaps: a literature review. Implement Sci 2010; 5: 11.

13 National Health and Medical Research Council. Research Translation Faculty. 2012. http://www.nhmrc.gov.au/research-translation/research-translationfaculty (accessed Sep 2013).

14 Runciman WB, Hunt TD, Hannaford NA, et al. CareTrack: assessing the appropriateness of health care delivery in Australia. Med J Aust 2012; 197: 100-105. https://www.mja.com.au/journal/2012/197/2/caretrack-assessingappropriateness-health-care-delivery-australia

15 French SD, McKenzie JE, O'Connor DA, et al. Evaluation of a theory-informed implementation intervention for the management of acute low back pain in general medical practice: the IMPLEMENT cluster randomised trial. PLOS One 2013; 8: e65471.

16 Artus M, van der Windt DA, Jordan KP, Hay EM. Low back pain symptoms show a similar pattern of improvement following a wide range of primary care treatments: a systematic review of randomized clinical trials. Rheumatology (Oxford) 2010; 49: 2346-2356.

17 Liberati A. Need to realign patient-oriented and commercial and academic research. Lancet 2011; 378: 1777-1778.

18 Silman AJ, Rudkin S. A national strategy for UK musculoskeletal clinical research: Arthritis Research UK clinical studies initiative. Rheumatology (Oxford) 2011; 50: 640-642. 